\title{
Changes in the Mechanical Strength of the Bone and in the Collagen Solubility of the Bone and the Skin of Carp Caused by $\beta$-Aminopropionitrile and D-Penicillamine
}

\author{
Reiji YoshinAKA*, Mamoru SATo*, and Shizunori IKEDA*
}

(Received September 8, 1976)

\begin{abstract}
$\beta$-Aminopropionitrile ( $\beta$-APN) and D-penicillamine, when administered orally to carp, caused a marked decrease in the mechanical strength of the vertebral column and an increase in the amount of soluble collagen in the bone and skin.

Intraperitoneal administration of these drugs to carp also caused a reduction in the mechanical strength of the bone.

When $\beta$-APN and D-penicillamine were added to acid-soluble collagen derived from normal carp skin, D-penicillamine, in contrast to $\beta$-APN, prevented the formation of stable collagen fibrils in vitro.

These results indicate that the skeletal deformity induced in carp by $\beta$-APN and Dpenicillamine is due to the reduced mechanical strength of the bone resulting from a collagen maturation defect.
\end{abstract}

Lathyrogens, exemplified by $\beta$-aminopropionitrile ( $\beta$-APN), have been shown to cause dramatic malformation of the skeleton and many other connective tissue abnormalities in rats ${ }^{1,2)}$ and chick embryos ${ }^{3}$. It has been reported that the administration of penicillamine to weanling rats and mice at the higher dosage levels results in osseous changes ${ }^{4,5)}$ similar to those produced by lathyrogens.

LEVENE and Gross ${ }^{3)}$ demonstrated that $\beta$-APN, when applied to the chorio-allantoic membrane of the chick embryo, produced a dramatic increase in fragility of the embryo and this alteration was accompanied by an increase in extractability of collagen from connective tissue into cold salt solution. NIMNI and BAvETTA ${ }^{\theta)}$ observed that penicillamine, when administered to rats, caused an accumulation of soluble collagen in their skin, a marked reduction of its tensile strength, and a delay in wound healing. It has been demonstrated that these changes in the mechanical strength and the collagen solubility of connective tissues in animals receiving $\beta$-APN and penicillamine are closely related to a defect in intramolecular and intermolecular cross-linking of collagen ${ }^{7-9)}$.

It was previously reported that $\beta$-APN and D-penicillamine produce pathologic changes in carp, Cyprinus carpio, ${ }^{10)}$ comparable to those in other animals induced by these drugs. These involve marked skeletal changes, consisting of spinal curvature, deformation of the ribs, fracture in the basal part of the rib, and hemorrhage in the fins, the skin, and the viscera. It seems reasonable to assume that these abnormalities reflect an abnormal pattern of collagen metabolism.

\footnotetext{
* Dept. Fish., Fac. Agr., Kyoto Univ., Kyoto, Japan（吉中禮二・传藤 守・池田静德：京都大学農学
} 部). 
The present paper describes the mechanical strength of the bone and the solubility of collagen of connective tissues in carp given $\beta$-APN and D-penicillamine.

\section{Materials and Methods}

Animals The same carp as reported previously ${ }^{10}$ were used in the present study. The details of the feeding conditions and the diet composition were described in a previous paper $^{10}$.

Measurement of breaking strength of the vertebral column The vertebral column was excised from a freshly killed carp, separated from the ribs, and cleaned of adhering tissue. Breaking strength of the vertebral column was measured by using a Reo-meter (RUD-J, Fuji Rika Ind. Co., Tokyo). Fig. 1 shows a schematic diagram of a Reo-meter

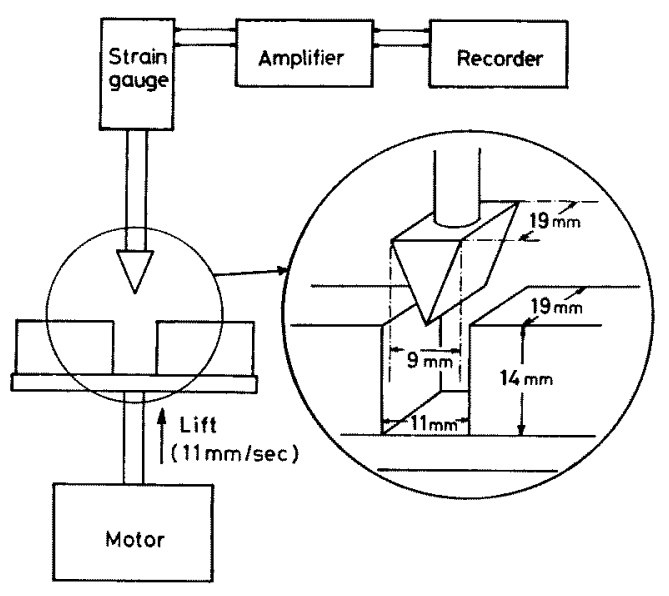

Fig. 1. Schematic diagram of the apparatus and its attachments for measuring the breaking strength of the vertebral column. and its attachments. The test specimen was placed on mobile platform. The force was recorded at that instant when the vertebral column was fractured in a lateral direction between the upper stationary attachment and the mobile platform which was ascending with a constant speed of $11 \mathrm{~mm}$ per sec. The average value of force required for fracture of the specimen between the 21st and the 22 nd vertebra and between the 26 th and the 27 th one, expressed in grams, represents the breaking strength.

Extraction and determination of collagen from the centra and the skin The vertebral column was separated from the ribs and the spines, and cleaned of adhering tissue. The skin was cleaned of scale and subcutaneous fat tissue. The cleaned centra and skin were frozen until the time of analysis. After mincing with scissors, these tissues (about $1.0 \mathrm{~g}$ of the centra, about $0.5 \mathrm{~g}$ of the skin) were shaken with $30-60$ volumes of $0.4 \mathrm{M} \mathrm{NaCl}$ for $40 \mathrm{hr}$ and centrifuged at $28,000 \times \mathrm{g}$ for $30 \mathrm{~min}$. The supernatant was dialyzed against a large volume of $0.1 \mathrm{M}$ acetic acid for 2 days. All these operations were performed at $5^{\circ} \mathrm{C}$. To obtain the insoluble collagen, the residue was solubilized with $30 \mathrm{~m} l$ of $5 \%$ trichloroacetic acid in a boiling water bath for $30 \mathrm{~min}$ and filtered through a filter paper. The filtrate was dialyzed overnight against running water. An aliquot of each fraction was hydrolyzed in $6 \mathrm{~N} \mathrm{HCl}$ in a sealed tube at $130^{\circ} \mathrm{C}$ for $3 \mathrm{hr}$. The hydrolysate was analyzed for hydroxyproline by the method of WoESSNER ${ }^{11}$. For expression as collagen the 
hydroxyproline values were multiplied by 10 .

Acid-soluble collagen from normal carp skin was extracted and purified by the method described previously ${ }^{12}$.

Thermal aggregation of collagen solution Acid-soluble collagen from normal carp skin was dissolved in $0.4 \mathrm{M} \mathrm{NaCl}-0.02 \mathrm{M}$ phosphate buffer, $\mathrm{pH}$ 7.0. The solution containing $0.1 \%$ carp skin collagen and $0.1 \mathrm{M} \beta$-APN or $0.1 \mathrm{M} \mathrm{D}$-penicillamine in $0.4 \mathrm{M}$ $\mathrm{NaCl}-0.02 \mathrm{M}$ phosphate buffer, $\mathrm{pH} 7.0$, was incubated at $25^{\circ} \mathrm{C}$ in a glass cuvette with a light path of $1.0 \mathrm{~cm}$. After the end of the incubation, the cuvette was cooled at $4^{\circ} \mathrm{C}$. The opacity of the solution was used as an index of aggregation and followed by measuring absorbance at $530 \mathrm{~nm}$ at various time intervals.

\section{Results}

Effect of the administration of $\boldsymbol{\beta}$-APN and D-penicillamine to carp on the breaking strength of their vertebral columns Carp weighing initially about $35 \mathrm{~g}$ were fed the control diet and the diet containing either $0.3 \% \beta$-APN or $0.3 \%$ D-penicillamine for 32 days. From each group, ten carp, which showed no skeletal deformity in appearance, were used for measuring the breaking strength of their vertebral columns. The breaking strength of each vertebral column from treated fish was plotted as a function of body length, since the breaking strength of those from normal carp was closely related to their body length, indicating that the coefficient of correlation between them was 0.958 . Oral administration of $\beta$-APN and D-penicillamine caused a marked decrease in the breaking i) strength of the vertebral column as shown in Figs. 2 and 3.

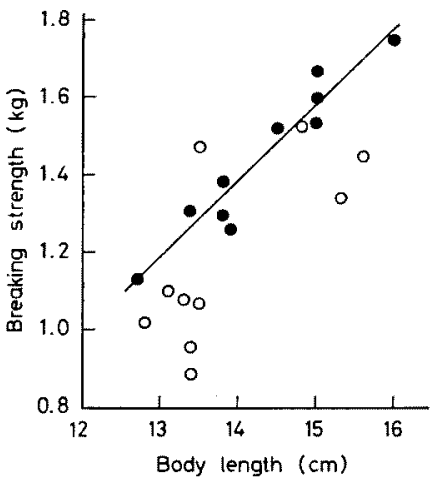

Fig. 2.

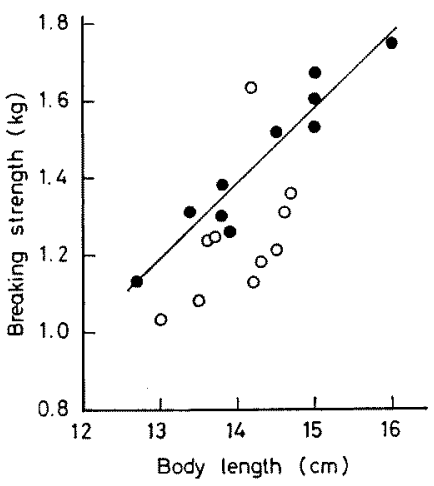

Fig. 3 .

Fig. 2. Breaking strength of the vertebral column from control carp and carp given orally $\beta-\mathrm{APN}$ for 32 days.

, control group; $O, \beta$-APN-treated group.

Fig. 3. Breaking strength of the vertebral column from control carp and carp given orally D-penicillamine for 32 days.

, control group; O, D-penicillamine-treated group. 
After having been fed the control diet for 7 weeks, each of ten carp was treated with drug. The fish were given intraperitoneally $0.1 \mathrm{mmole}$ of $\beta$-APN or D-penicillamine $/ 100 \mathrm{~g}$ of body weight daily for 3 days. After the administration of the drugs being discontinued for next 4 days, they were again injected with each drug in same manner for 3 days. At the end of the experimental period, six fish survived in the former group and eight survived in the latter. The breaking strength of the vertebral column from each surviving carp was measured. The results obtained are shown in Figs. 4 and 5. The vertebral column

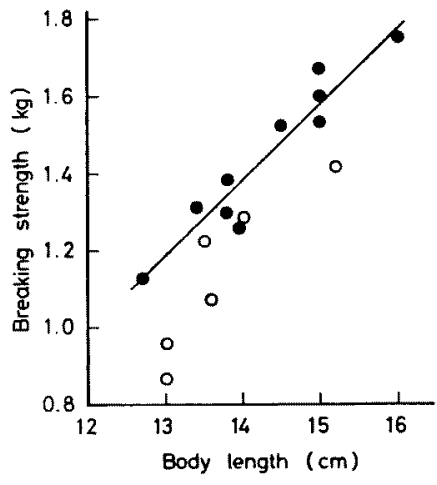

Fig. 4.

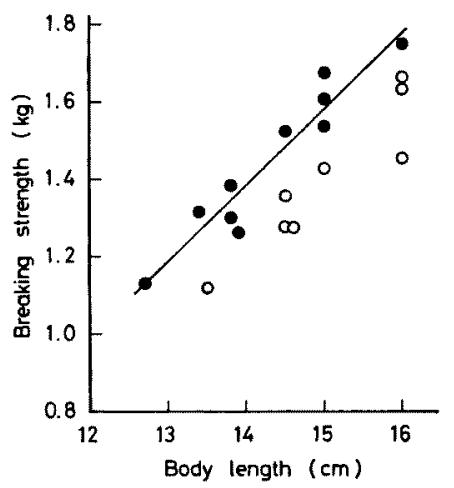

Fig. 5.

Fig. 4. Breaking strength of the vertebral column from control carp and carp given intraperitoneally $\beta$-APN.

, control group; $O, \beta$-APN-treated group.

Fig. 5. Breaking strength of the vertebral column from control carp and carp given intraperitoneally D-penicillamine.

- control group; 0 , D-penicillamine-treated group.

of fish injected with each drug had significantly lower breaking strength than the control. These results resemble those obtained when fish were given orally each drug as abovementioned.

It seems reasonable to assume that this reduction in the breaking strength of the bone is related to the manifestation of skeletal deformity in carp treated with these drugs as described previously ${ }^{10)}$.

Effect of oral administration of $\boldsymbol{\beta}$-APN and D-penicillamine to carp on the solubility of collagen of their centra and skin Carp were fed the control diet and the diet containing either $0.3 \% \beta$-APN or $0.3 \%$ D-penicillamine for 32 days and sacrificed for comparing the patterns of collagen solubility in their centra and skin. The results are shown in Table 1. The amount of collagen extracted by $0.4 \mathrm{M} \mathrm{NaCl}$ from the centra was significantly increased in both groups given drugs but the total amount of collagen per $g$ of the fresh tissue was not altered significantly as a result of the administration of drugs. A significant increase in the amount of neutral salt-soluble collagen of the skin was also 
Table 1. Collagen content of the soluble and insoluble fractions in the centra and the skin of control carp and those given orally $\beta$-APN or D-penicillamine for 32 days

\begin{tabular}{lllccc}
\hline \hline \multirow{2}{*}{ Tissue } & Group & \multicolumn{3}{c}{ Collagen $(\mathrm{mg} / \mathrm{g}$ of wet tissue) } & \multicolumn{2}{c}{$\begin{array}{c}\text { Soluble } \\
\text { collagen } \\
(\%)\end{array}$} \\
\cline { 3 - 6 } & & $\begin{array}{c}0.4 \mathrm{M} \mathrm{NaCl} \\
\text { soluble }\end{array}$ & Insoluble & Total & \\
\hline \multirow{3}{*}{ Centra } & Control & $2.0 \pm 0.6$ & $54.0 \pm 3.2$ & $56.0 \pm 3.6$ & $3.5 \pm 0.9$ \\
& $\beta$-APN & $4.1 \pm 1.1^{*}$ & $50.2 \pm 3.1$ & $54.4 \pm 3.9$ & $7.5 \pm 1.7^{*}$ \\
& D-Penicillamine & $4.6 \pm 0.5^{*}$ & $56.6 \pm 9.0$ & $61.1 \pm 9.2$ & $7.5 \pm 1.1^{*}$ \\
\hline \multirow{3}{*}{ Skin } & Control & $14.2 \pm 2.6$ & $225.0 \pm 18.3$ & $239.2 \pm 17.8$ & $6.0 \pm 1.2$ \\
& $\beta$-APN & $30.4 \pm 10.5^{*}$ & $215.3 \pm 25.7$ & $245.7 \pm 22.3$ & $12.5 \pm 4.4^{*}$ \\
& D-Penicillamine & $32.3 \pm 5.8^{*}$ & $189.6 \pm 24.8^{* *}$ & $221.8 \pm 20.9$ & $14.8 \pm 3.8^{*}$ \\
\hline
\end{tabular}

Each value represents the mean \pm S.D. for 5 fish.

* Significant difference $(\mathrm{P}<0.01)$ compared to the control group.

** Significant difference $(0.01<\mathrm{P}<0.05)$ compared to the control group.

observed in fish given drugs. The amount of insoluble collagen of the skin was slightly decreased only in the penicillamine-treated group. However, the amount of total collagen of the skin did not vary among the three groups. These results seem to indicate that $\beta$-APN and D-penicillamine inhibited the process in the conversion of soluble collagen to insoluble one, that is, in the formation of intramolecular and intermolecular cross-links.

Effect of the addition of $\beta$-APN

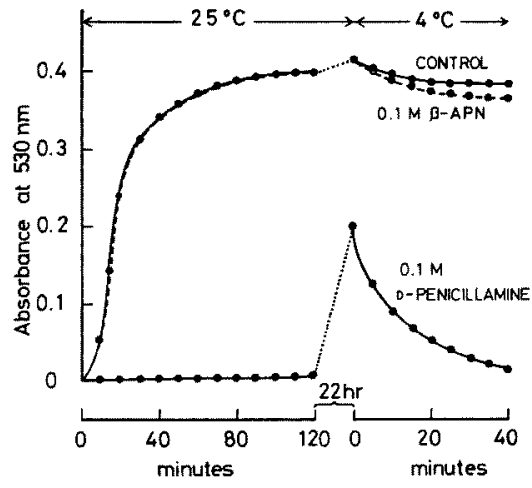

Fig. 6. Effect of the addition of $\beta-A P N$ or $D-$ penicillamine to normal carp skin collagen on thermal aggregation and redissolution.

Acid-soluble collagen $(0.1 \%)$ in $0.4 \mathrm{M}$ $\mathrm{NaCl}$ buffered to pH 7.0 with $0.02 \mathrm{M}$ sodium phosphate was incubated at $25^{\circ} \mathrm{C}$ for $24 \mathrm{hr}$ and then cooled to $4^{\circ} \mathrm{C}$. Test solution contained $0.1 \mathrm{M} \beta$-APN or $0.1 \mathrm{M}$ D-penicillamine. Aggregation of collagen solution and the redissolution of the gel were followed by measuring absorbance at $530 \mathrm{~nm}$ at various time intervals. and D-penicillamine on the thermal aggregation of acid-soluble collagen from normal carp skin To test the mechanism of action of $\beta-A P N$ and $D$ penicillamine in vivo, it seemed appropriate to investigate how the addition of these drugs to acid-soluble collagen from normal carp skin would affect the fibril formation in vitro and the stability of the fibrils formed. The result is shown in Fig. 6. $\beta$-APN at concentration of $0.1 \mathrm{M}$ did not affect the thermal aggregation of normal acid-soluble collagen, while D-penicillamine at same concentration caused a delay and an inhibition in the aggregation process. After storage at $25^{\circ} \mathrm{C}$ for $24 \mathrm{hr}$ to stabilize the aggregated gel, and the gel was colled to $4^{\circ} \mathrm{C}$. Upon cooling, the gel containing $\beta$-APN as well as the 
control gel showed a small degree of redissolution, whereas the gel containing penicillamine dissolved rapidly. The formation of the fibrils from collagen solution in vitro has been shown to depend not only upon covalent intermolecular cross-links ${ }^{13}$ ) but also upon noncovalent forces, mainly hydrophobic interactions ${ }^{14)}$. The reconstituted collagen fibrils without covalent bonds redissolve when cooled at $4^{\circ} \mathrm{C}$, since the hydrophobic interactions stabilizing the molecular assembly are weakened at this temperature ${ }^{5}$. Therefore the result obtained suggests that penicillamine added to normal collagen solution, in contrast to $\beta$-APN, prevents the formation of stable intermolecular cross-links in vitro.

\section{Discussion}

The administration of $\beta$-APN or D-penicillamine to carp causes a decrease in the breaking strength and an increase in the amount of $0.4 \mathrm{M} \mathrm{NaCl}$-soluble collagen in the centra and the skin. These findings agree with those that were seen in chick embryos ${ }^{3}$ and rats $^{6}$.

Connective tissue has unique properties such as its high mechanical strength and low solubility of its constituted structural protein, and these properties are mainly related to the formation of covalent cross-links in collagen and elastin ${ }^{16)}$. These cross-links have been shown to be Schiff base formed between lysyl-derived aldehyde residue and $\varepsilon$-amino group of lysyl or hydroxylysyl residue ${ }^{16-18)}$. It is now accepted that the initial step in the cross-linking of both collagen and elastin is the enzymic oxidative deamination of peptidebound lysine to $\alpha$-aminoadipic- $\delta$-semialdehyde (allysine). PINnel and MARTIN ${ }^{19)}$ demonstrated that lysyl oxidase capable of converting lysyl residues to allysyl residues in elastin is present in extracts of embryonic chick bone. Subsequently, SIEGEL and MARTIN ${ }^{20)}$ found that lysyl oxidase prepared from chick bone catalizes the initial step in the crosslinking of collagen. $\beta$-APN acts as a potent inhibitor of lysyl oxidase in vitro and in vivo ${ }^{19-22)}$. The collagen from animals receiving $\beta$-APN has been shown to have decreased amounts of aldehyde ${ }^{8}$, which is possibly due to the inhibition of lysyl oxidase. It seems, therefore, reasonable to assume that the decrease in the breaking strength of the bone and the increase in the collagen solubility of connective tissues observed in carp given $\beta$ APN may be due to the inhibition of lysyl-to-allysyl conversion by it.

It has been shown that the inhibition of the cross-linking of collagen induced by D-penicillamine is dose-dependent ${ }^{5}$. At relatively low dose, penicillamine acts primarily by blocking aldehyde groups on newly synthesized collagen molecules; at higher dose, it inhibits lysyloxidase activity possibly by chelating divalent cations or by interacting with other cofactors such as pyridoxal. In the present study, carp were given relatively low dose of penicillamine (about $9 \mathrm{mg} / 100 \mathrm{~g}$ of body weight/day) in comparison with the dosage made for rats $^{5,7,8)}$. Nevertheless, D-penicillamine caused marked changes in the mechanical strength of the bone and in the collagen solubility of connective tissues of 
carp. Therefore, these changes may be due to the inhibition of the collagen cross-linking in which the blockage of aldehydes on collagen is mainly involved. This is supported by the experiment showing that D-penicillamine, in contrast to $\beta-A P N$, prevented the formation of stable collagen fibrils when reconstituted in vitro.

Consequently, it seems reasonable to assume that skeletal deformity observed in carp given $\beta$-APN or D-penicillamine ${ }^{10)}$ might be caused by the reduction of the mechanical strength of the bone as a result of abnormality of the collagen metabolism even though underlying mechanism may be different between $\beta$-APN and D-penicillamine.

The results obtained in the present study suggest that our attention should be paid to collagen metabolism of fishes as well in order to elucidate underlying mechanisms in the manifestation of deformed fishes which has been observed hitherto.

This work was partly supported by a grant from the Ministry of Education of Japan.

\section{References}

1) P. Ramamurti and H. E. TAylor: Lab. Invest., 7, 115-125 (1958).

2) J. J. Lalich and D. M. Angevine: Arch. Path., 90, 22-28 (1970).

3) C. I. Levene and J. Gross: J. Exp. Med., 110, 771-789 (1959).

4) D. Jacobus, M. Grenan, B. Wagner, C. Margolis, and I. Jaffe: Amer. J. Path., 54, 21-33 (1969).

5) M. E. Nmint K. Deshmukh, and N. Gerth: Nature, 240, 220-221 (1972).

6) M. E. Nmini and L. A. BAvetta: Science, 150, 905-907 (1965).

7) M. E. Nimni: J. Biol. Chem., 243, 1457-1466 (1968).

8) K. Deshmukh and M. E. Nimni: ibid., 244, 1787-1795 (1969).

9) K. Deshmukh, M. Just, and M. E. Nimni: Clin. Orthop. Relat, Res., 91, 186-196 (1973).

10) M. Sato, R. YoshinakA, and S. IKedA: This Bull., 43, 349-355 (1977).

11) J. F. Woessner, Jr.: Arch. Biochem. Biophys., 93, 440-447 (1961).

12) R. Yoshinaka, M. SAto, and S. IKEDA: This Bull., 42, 455-463 (1976).

13) A. Deshmukh, K. Deshmukh, and M. E. Nimni: Biochemistry, 10, 2337-2342 (1971).

14) J. M. CASsel and R. G. Christensen: Biopolymers, 5, 431-437 (1967).

15) K. A. PIEZ: Annu. Rev. Biochem., 37, 547-570 (1968).

16) A. J. BaIley and C. M. PeACH: Biochem. Biophys. Res. Commun., 33, 812-819 (1968).

17) A. J. Bailey, C. M. PeACH, and L. J. Fowler: Biochem. J., 117, 819-831 (1970).

18) K. Deshmukh and M. E. Nimni: Biochem. Biophys. Res. Commun., 46, 175-182 (1972).

19) S. R. Pinnell and G. R. Martin: Proc. Natl. Acad. Sci. U.S.A., 61, 708-716 (1968).

20) R. C. Siegel and G. R. MARTIN: J. Biol. Chem., 245, 1653-1658 (1970).

21) R. C. Siegel, S. R. Pinnel, and G. R. Martin: Biochemistry, 23, 4486-4492 (1970).

22) A. S. Narayanan, R. C. Siegel, and G. R. Martin: Biochem. Biophys. Res. Commun., 46, 745751 (1972). 